\title{
Interference Analysis between Mobile Radio and Digital Terrestrial Television in the Digital Dividend Spectrum
}

\author{
Alberto TEKOVIC ${ }^{1}$, Davor BONEFACIC ${ }^{2}$, Gordan SISUL ${ }^{2}$, Robert NAD ${ }^{2}$ \\ ${ }^{1}$ Access and Transport Network Engineering, VIPnet Ltd., Vrtni put 1, 10000 Zagreb, Croatia \\ ${ }^{2}$ Dept. of Radiocommunications, Faculty of Electrical Engineering and Computing, Unska 3, 10000 Zagreb, Croatia
}

a.tekovic@vipnet.hr, \{davor.bonefacic, gordan.sisul,robert.nadj\}@fer.hr

Submitted March 31, 2016 / Accepted November 19, 2016

\begin{abstract}
This paper is concerned with the analysis of adjacent channel interference of the Long Term Evolution (LTE) mobile system operating in the Digital Dividend into Digital Video Broadcasting - Terrestrial (DVB-T) system. Field measurements in the real LTE network have been conducted in order to define the most significant scenarios and for each of these, Protection Ratios have been quantified. Variable load on the LTE base station has been taken into consideration. Therefore, Protection Ratios for the LTE base station in idle state, and fully dedicated mode have been calculated. Interference mitigation techniques have been reviewed, and an effective deployment method has been proposed.
\end{abstract}

\section{Keywords}

Adjacent-channel interference, LTE FDD, DVB-T, Digital Dividend, Protection Ratio, Protection Distance, mitigation technique

\section{Introduction}

Due to greater spectrum efficiency, switching to digital terrestrial TV broadcasting frees part of the UHF spectrum from $790 \mathrm{MHz}$ to $862 \mathrm{MHz}$ called "digital dividend". The transition process is already completed in many countries. Ever increasing market interest for mobile broadband communications was a main driver for allocating the digital dividend to mobile services in several regions of the world, which occurred at the World Radiocommunication Conference in 2007 (resolution 749) [1]. Although this allocation began in 2015, some EU countries were allowed to utilize this allocation before 2015 [2], with necessary technical coordination with neighboring countries. This decision was very positive from the market point of view, but raised new co-existence issues that need to be carefully analyzed and evaluated:

- co-channel interference between neighboring countries or regions, one of them using the digital dividend band for mobile systems and the other for analog or digital terrestrial television [3], [4]

- adjacent channel interference within a given territory, where frequencies up to $790 \mathrm{MHz}$ will be used for television and those immediately above this limit will be used for mobile radio communications

- co-channel interference within a given territory in the digital dividend band between mobile systems and DVB-C2 [5].

The theoretical analysis of co-channel interference between mobile system and digital terrestrial television has been presented in [6-8]. This is followed by experimental studies based on Monte Carlo simulations, aiming to define co-existence thresholds. Several scenarios between DVB-T and LTE FDD, such as co-channel and adjacent-channel interferences, variation of distance between DVB-T and LTE devices, and different directions of link have been studied in [9]. Co-existence in terms of DVB-T access coverage loss and outage probability has been studied in [10] and [11].

In [12] and [13], simulation analyses are carried out to estimate the adjacent channel interfering effects of LTE Base Station (eNodeB) and User Equipment (UE) on DVB-T receiver systems, through the computation of the correspondent Protection Distance (PD). In both works, the power density spectrum of LTE signals has been approximated using the spectrum Block Emission Masks (BEM) reported on the ETSI recommendations ETSI TS 136104 V8.7.0 for LTE base stations. In recent work [14], the adjacent channel interference effects of the LTE FDD DL on DVB-T home receivers (only for channel 60) have been simulated, Protection Ratio (PR) as well as the Protection Distance between eNodeB and DVB-T receivers have been calculated. The LTE Downlink Link Level Simulator tool [15] has been used to generate the transmission from a base station to two registered users in a $2 \times 2$ MIMO mode. Coexistence between digital terrestrial television and LTE network in the new spectrum allocated from mobile communications $700 \mathrm{MHz}$ band has been investigated in [16]. 
After theoretical analysis and simulations, in order to measure the impact of the interfering LTE system on the DVB-T system, appropriate experimental laboratory test beds have been used and results have been presented in [17-23]. Results from laboratory and conducted field tests cannot be directly compared, due to different DTT standard and LTE parametrization used in those tests. For example, high dependence of the digital TV signal power to interfering signal power ratio on the bandwidth of the interfering signal and applied FEC protection has been measured in [18]. However, significant PR value offset between channel 60, and channels 58-59 has been confirmed, both in laboratory [17-23] and conducted field test.

Taking into account the power density spectrum load dependency of an eNodeB signal, the present paper aims to provide an effective contribution in the comparison of the PR and PD results obtained from the field measurements with results obtained from the simulations [12-14], and results obtained from laboratory measurements [17-23]. Conclusions from [14] on the irrelevancy of adjacent channel interference cases LTE FDD UL interfering the DVB-T at the analyzed TV receiver, and DVB-T transmitter interfering the LTE FDD DL at the considered UE receiver have been confirmed in the conducted field measurements. Therefore, the adjacent channel interference case where LTE FDD DL interferes with DVB-T at the considered TV receiver is in the main focus of this paper.

The rest of this paper is structured as follows. Section 2 introduces terminology used throughout this paper and defines the main configuration parameters for DVB-T and LTE systems used in the test bed. Section 3 describes investigated interference scenarios and presents PR results. Section 4 explains proposed interference mitigation techniques. Finally, Section 5 presents our conclusions.

\section{Measurement Setup}

\subsection{DVB-T QoS Metrics Definition}

In order to evaluate the impact of interference, parameter Carrier-to-Noise ratio $(\mathrm{C} / \mathrm{N})$ defined as the ratio between the total received DVB-T power and total received LTE signal power has been used. The minimum Carrier-to-Noise ratio that assures a stable and sufficient service quality at the DVB-T receiver defines the Protection Ratio (PR) [24]. Quality of Service can be expressed on an objective or subjective basis. In the first case, the parameters Bit Error Rate (BER), the Packet Error Rate (PER), and the Modulation Error Rate (MER) can be used [20]. Unfortunately, BER, PER, and MER values usually are not available in consumer-grade DVB-T receivers. Therefore, the subjective method has been used in the interference analysis, and the most common metrics are the Picture Failure (PF), and the Subjective Failure Points (SFP) [21]. In order to be able to compare field measurement and simulation results, Protection Distance (PD) has also been calculated in Sec. 4 The PD parameter is defined as the minimum distance between an LTE Base Station (BS) or User Equipment (UE) antenna and a DVB-T receiving antenna in order to make the interference effects at the DVB-T front-end acceptable in terms of quality of service.

\subsection{DVB-T and LTE Configuration}

DVB-T is the victim system in the analyzed scenarios. The conducted, and in this paper presented, measurement results are part of a study conducted for a mobile operator. The study goal was to clarify the magnitude of expected interference issues. Therefore, parameters for the wanted signal source (Tab. 1) have been selected in order to be compliant with operating DVB-T network in the Republic of Croatia. The desired DVB-T signal has been generated using the Rohde\&Schwarz SFE 100 test transmitter for channels 50 to 60 . Two typical DVB-T signal level (at DVB-T receiver) scenarios have been considered: $-50 \mathrm{dBm}$ and $-70 \mathrm{dBm}$.

The DVB-T receiver side is characterized by several parameters including receiver Selectivity $\left(S_{\mathrm{x}}\right)$ and the minimum Carrier-to-Noise ratio $\left(C / N_{\min }\right)$ required [25] for a satisfying signal reception quality, presented in Tab. 2 for 64-QAM modulation.

Due to limited time available for carrying out the planned field test measurements, the number of DVB-T receivers used in the measurements has also been limited. Therefore, two products belonging to consumer-middle quality range (Nytro Box NB-4001T, Strong SRT 8100 $\mathrm{HD}$ ), and one product belonging to consumer-lower quality range (NotOnlyTV- Scart DVB-T REC) have been used in field tests.

LTE is the interfering system in this analysis. As well as for DVB-T system, parameters for LTE system have been selected (Tab. 3) in accordance to radio network parameters planned for the rollout of the commercial LTE

\begin{tabular}{|c|c|}
\hline Parameter & Value \\
\hline Multiple Access & OFDM \\
\hline FEC & $3 / 4$ \\
\hline FFT points & $8 \mathrm{~K}$ \\
\hline Guard interval & $1 / 4$ \\
\hline Signal Level [dBm] & $-50 /-70$ \\
\hline Modulation & 64 QAM \\
\hline
\end{tabular}

Tab. 1. DVB-T parameters used in field tests.

\begin{tabular}{|c|c|c|c|c|}
\cline { 3 - 5 } \multicolumn{2}{c|}{} & \multicolumn{3}{c|}{$\begin{array}{c}\text { Required C/N (dB) for BER }=\mathbf{2} \times \mathbf{1 0}^{-4} \text { after } \\
\text { Viterbi QEF after Reed- Solomon }\end{array}$} \\
\hline Modulation & $\begin{array}{c}\text { Code } \\
\text { Rate }\end{array}$ & $\begin{array}{c}\text { Gaussian } \\
\text { channel }\end{array}$ & $\begin{array}{c}\text { Ricean } \\
\text { channel (F1) }\end{array}$ & $\begin{array}{c}\text { Rayleigh } \\
\text { channel (P1) }\end{array}$ \\
\hline 64- QAM & $1 / 2$ & 13.8 & 14.3 & 16.4 \\
\hline 64- QAM & $2 / 3$ & 16.7 & 17.3 & 20.3 \\
\hline 64- QAM & $3 / 4$ & 18.2 & 18.9 & 23.0 \\
\hline $64-$ QAM & $5 / 6$ & 19.4 & 20.4 & 26.2 \\
\hline $64-$ QAM & $7 / 8$ & 20.2 & 21.3 & 28.6 \\
\hline
\end{tabular}

Tab. 2. DVB-T Minimum C/N for 64-QAM [21]. 


\begin{tabular}{|c|c|}
\hline Parameter & Value \\
\hline Multiple Access & OFDMA \\
\hline Duplex mode & FDD \\
\hline Channel bandwidth [MHz] & 10 \\
\hline Number of resource blocks & 50 \\
\hline Number of OFDM sub-carriers & 12 \\
\hline Sub- carrier bandwidth [kHz] & 15 \\
\hline Channel modulation & 64 QAM \\
\hline Output power [dBm] & $23-43(1 \mathrm{~dB}$ step) \\
\hline MIMO & $2 \times 2$ \\
\hline Number of users (active test) & 1 \\
\hline eNodeB & Ericsson 6601 (main- remote) \\
\hline
\end{tabular}

Tab. 3. LTE parameters used in field tests.

network in the digital dividend spectrum. Ericsson's 6601 main-remote eNodeB solution has been used, and for the antenna system RFS antenna model APXV9R20B-C [26] has been selected. Tests have been carried out in 3 consecutive $10 \mathrm{MHz}$ bands starting from $791 \mathrm{MHz}$ (band A: $791 \div 801 \mathrm{MHz}$; band $\mathrm{B}$ : $801 \div 811 \mathrm{MHz}$; band $\mathrm{C}$ : $811 \div 821 \mathrm{MHz})$.

Having in mind that the data load on an eNodeB will vary during the day, two uttermost cases have been observed:

- Idle mode (Fig. 1) represents the eNodeB mode when there are no user data in the downlink direction to be carried out. Therefore, during this state, the following has been transmitted over the air interface: Control Format Indicator (CFI) mapped to the Physical Control Format Indicator Channel (PCFICH). CFI's sole purpose is the dynamic indication of a number of OFDMA symbols reserved for control information. Downlink Control Information (DCI) with different formats basically controls all the physical layer uplink and downlink resource allocation, and it is mapped on the Physical Downlink Control Channel (PDCCH). Last are Reference Signals (RS), with their purpose to deliver the reference point for the downlink power. The number of reference signals depends on the antenna system configuration deployed [27].

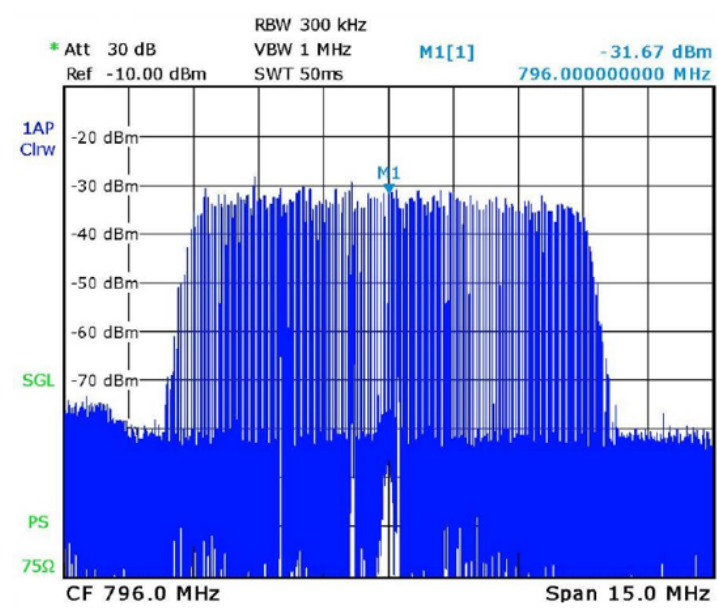

Fig. 1. LTE DL signal spectrum in idle mode (band A).

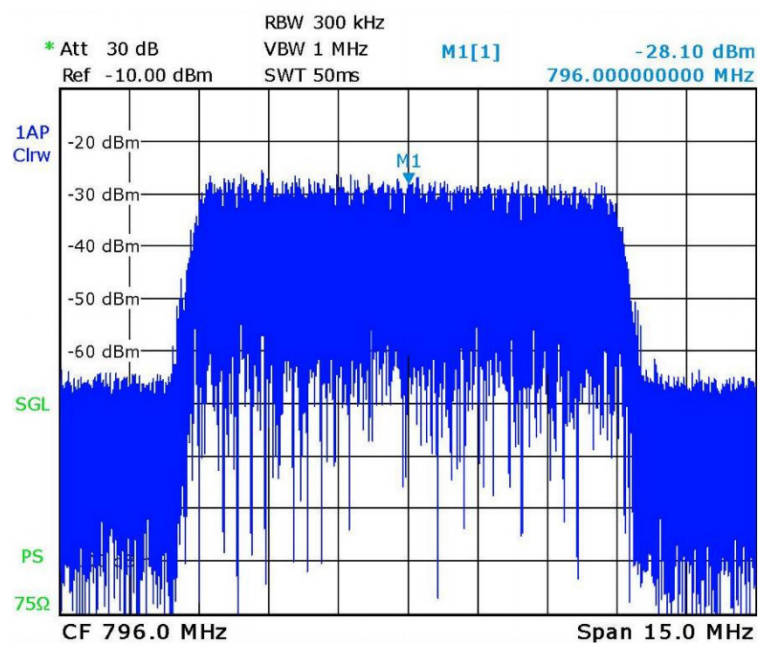

Fig. 2. LTE DL signal spectrum in dedicated mode (band A).

- Dedicated mode (Fig. 2) represents the eNodeB mode, where user data have been transmitted in the downlink direction on the Physical Downlink Shared Channel (PDSCH). Exclusive test terminal access to eNodeB has been assured by using the eNodeB service lock mode functionality (IMSI filtering). The use of the User Datagram Protocol (UDP) download service assured continuous allocation of all available Physical Resource Blocks (PRB) to the test client. For the UDP download service on the client side, a notebook with the USB data card Huawei E392U-12 (category 4) has been used. In order to assure continuous maximum allowed (set) eNodeB output power transmission, the UDP client has been placed at the LTE cell edge $(\mathrm{RSPR} \leq-110 \mathrm{dBm})$.

The signal power has been measured using a spectrum analyzer with the following parameter setup: Span $=15 \mathrm{MHz}, \mathrm{RBW}=100 \mathrm{kHz}, \mathrm{VBW}=1 \mathrm{MHz}$. For the DVB-T signal power has been measured in the $8 \mathrm{MHz}$ channel bandwidth, and for the LTE, in the $10 \mathrm{MHz}$ channel bandwidth.

\section{Scenarios and PR Results}

The scope of these field measurements was to investigate all possible scenarios which could have a significant impact on DVB-T reception, to define most critical scenarios and to calculate PR and PD for those scenarios. Scenarios where LTE FDD DL is interfering the DVB-T at the considered TV receiver is considered the most critical. In order to deeply analyze this scenario, three most common DVB-T receiving antenna system configurations have been considered:

- DVB-T receiving antenna system uses outdoor mounted antenna without masthead amplifier,

- DVB-T receiving antenna system uses outdoor mounted antenna with masthead amplifier, 
- DVB-T receiving antenna system uses indoor active antenna.

The last antenna system configuration which uses indoor active antenna is not considered an approved DVB-T receiving antenna system configuration by the Croatian authorities, and therefore does not have a legal right to protection, but it is expected to be used in significant number of households, as active indoor antennas are widely available on the market. In order to achieve results that will apply to real life conditions, the desired DVB-T and interfering LTE signal have been generated over the air interface. At first, measurements have been conducted in the clear optical view condition, which represents a typical Gaussian channel environment. Measurement in the Gaussian channel for the two most relevant scenarios have been presented in this paper.

In order to measure PR, the desired DVB- $\mathrm{T}$ signal has been fixed to $-50 \mathrm{dBm}$ and $-70 \mathrm{dBm}$ power respectively. The interfering LTE signal power has been set to minimum $(23 \mathrm{dBm})$, and then increased in steps of $1 \mathrm{~dB}$ until the PF occurred. Then, the LTE signal power was decreased to the SFP, which has been defined as the minimum Carrier-to-Noise Ratio value that guarantees a 60second period free from picture artifacts. Results presented in this paper correspond to the mean value of three consecutive independent measurements for every SFP point.

\subsection{LTE DL Interfering DVB-T System using Outdoor Receiver Antenna without Masthead Amplifier}

Figure 3 represents the scenario where, for DVB-T reception, an outdoor mounted antenna without a masthead amplifier has been used. The scenario is typical for private households in areas with a satisfying DVB-T signal level.

The PR for each DVB-T receiver has been presented with a different color in Fig. 4. PR for idle measurement has been displayed with a solid line, while PR for dedicated measurement with a dashed line. The mark on each graph line presents the case in which interference caused Picture Failure (PF). There is no mark on channels where PF has not occurred even for the highest LTE output power.

Despite the fact that the LTE DL channel signal strength for an eNodeB operating in idle mode is $9 \mathrm{~dB}$ lower than the dedicated mode, it can be concluded (Fig. 4)

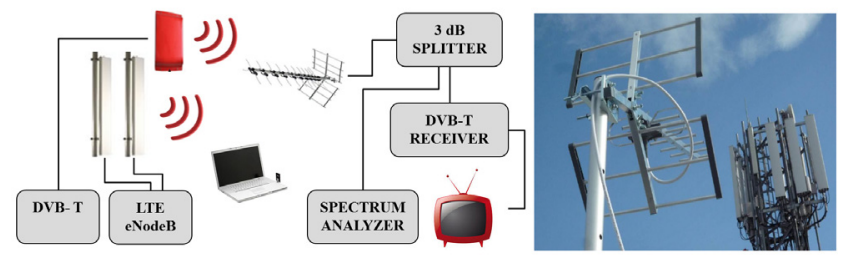

Fig. 3. DVB-T receiver system without masthead amplifier, schematic (left) and actual test setup (right).

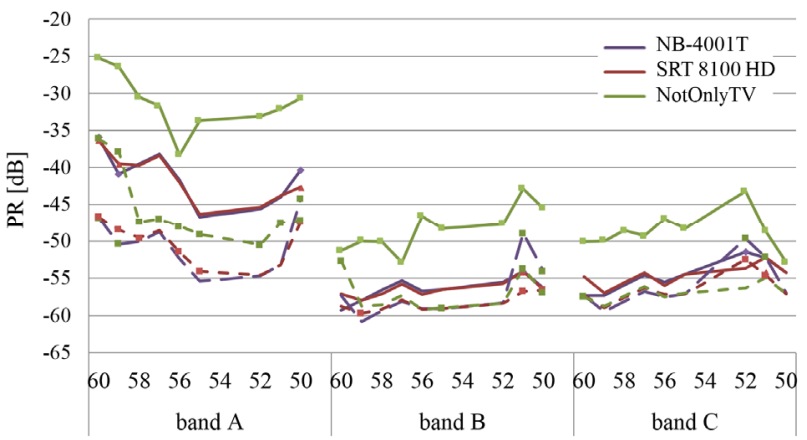

Fig. 4. Protection Ratio (PR) for DVB-T received signal $-70 \mathrm{dBm}$, DVB-T antenna system without masthead amplifier, LTE idle (solid line); LTE dedicated (dashed line).

that the DVB-receivers are more sensitive to the idle LTE channel. A similar manifestation has been noticed in [17] for the LTE-UL scenario. Therefore, approximately $10 \mathrm{~dB}$ higher PR is needed for the idle state for eNodeB operating in band $\mathrm{A}$, and approximately $5 \mathrm{~dB}$ for eNodeB operating in band $\mathrm{B}$ or $\mathrm{C}$.

Visible variation in PR thresholds for various DVB-T receivers can be observed, with lower quality receivers requiring higher $\mathrm{PR}$. As expected, the worst performance has been achieved while LTE was operating in band A, since this is the band closest to the DVB-T operating band. PR increases for channels 50, 51, and 52 due to the image frequency issue, which is typical for superheterodyne DVB-T receivers. Superheterodyne tuners are susceptible to image channel interference when the interferer appears nine channels above the wanted channel. Silicon tuners have a low, or zero, intermediate frequency and do not suffer from the same $N+9$ image problems as superheterodyne receivers [28].

In PR measurement for the DVB-T received signal $-50 \mathrm{dBm}$ (Fig. 5), the interfering LTE signal was not strong enough to provoke PF for consumer-middle quality range receivers (NB 40001T, SRT 8100 HD). Therefore, $\mathrm{PF}$ only for consumer-low quality range receiver (NotOnlyTV-Scart DVB-T REC) has been recorded.

In order to increase the interfering signal level, measurements have been continued in the lab environment

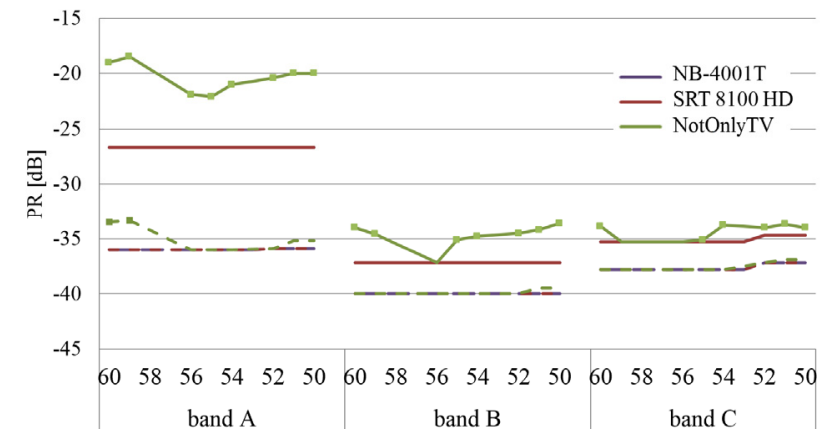

Fig. 5. Protection Ratio (PR) for DVB-T received signal $-50 \mathrm{dBm}$, DVB-T antenna system without masthead amplifier, LTE idle (solid line); LTE dedicated (dashed line). 


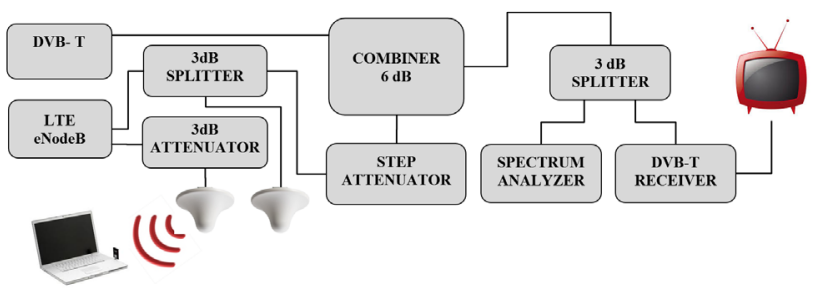

Fig. 6. Measurement setup for DVB-T received signal $-50 \mathrm{dBm}$ in lab environment.

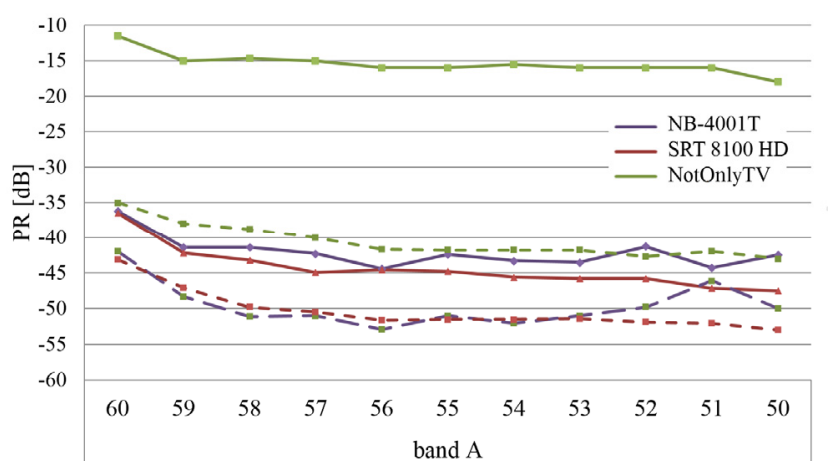

Fig. 7. Protection Ratio (PR) for DVB-T received signal $-50 \mathrm{dBm}$, DVB-T antenna system without masthead amplifier, LTE idle (solid line); LTE dedicated (dashed line) - laboratory measurements.

(Fig. 6), and results for PR have been presented in Fig. 7. Here only LTE DL in band A has been considered, as, according to previous measurements, in that band the largest PR is expected.

PR results (Figs. 4, 5, 7) for the dedicated measurement mode are compliant to results obtained in [9] and [24].

\subsection{LTE DL Interfering DVB-T System using Outdoor Receiver Antenna with Masthead Amplifier}

Figure 8 represents the scenario where the DVB-T receiving antenna system uses an outdoor mounted antenna with a masthead amplifier [29]. The scenario is typical for private households in areas where DVB-T signal level or quality is low, and on multi-tenant buildings regardless of the DVB-T signal quality condition. For this test scenario, wideband (channels $21 \div 69$ ) masthead amplifier with $22 \mathrm{~dB}$ gain has been used. The wideband amplifier amplifies the desired DVB-T, but also the interfering LTE signal. Due to the increased signal level, the amplifier will operate in its nonlinear range, and it will generate intermodulation products. A mixture of amplified desired signal together with interference and intermodulation products will reach the DVB-T input port [21]. Increased signal level will reduce DVB-T receiver selectivity, and also the nonlinear range could be reached. All of the mentioned will cause a signal degradation and PF.

In this scenario (Fig. 9), only the SRT 8100 HD receiver has been tested, because in the previous measure-

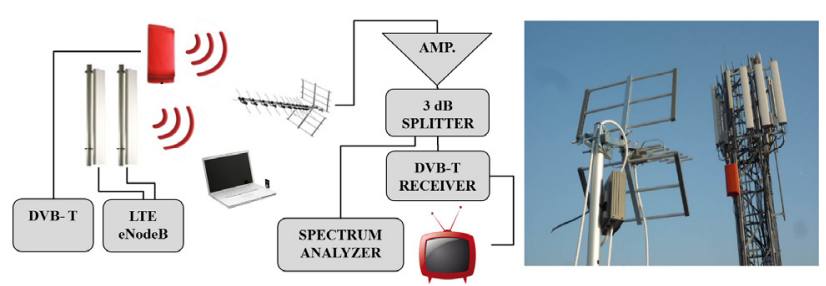

Fig. 8. DVB-T receiver system with masthead amplifier, schematic (left) and actual test setup (right).

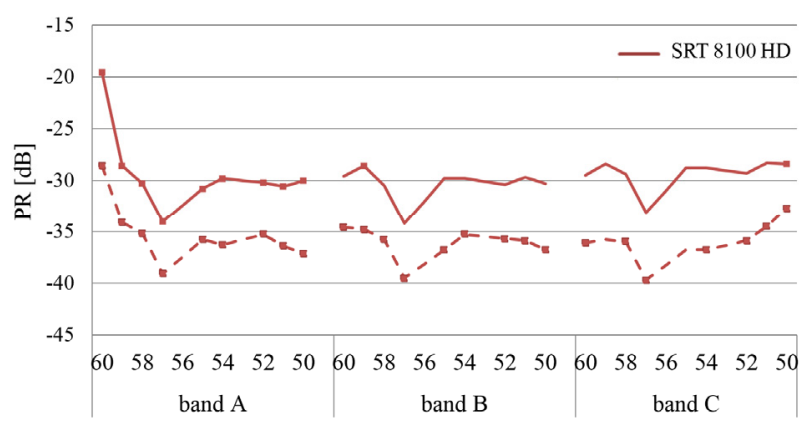

Fig. 9. Protection Ratio (PR) for DVB-T received signal $-70 \mathrm{dBm}$, DVB-T antenna system with masthead amplifier, LTE idle (solid line); LTE dedicated (dashed line).

ment both consumer-middle quality range receivers behaved similarly, and much worse behavior has been observed for the consumer-low quality range receiver. Comparing Fig. 4 and Fig. 9, significant PR increase can be observed for the scenario when the masthead amplifier has been used. For this scenario, it is also true that the PR is higher for channels 59 and 60.

Once again, the worst performance can be observed for the eNodeB operating in band A and an idle LTE DL interfering signal presents the worst case. PF occurred for idle and dedicated case while eNodeB was operating in band A. For eNodeB operating in bands B and C, PF occurred only in idle case.

\subsection{LTE DL and GSM900 DL Interfering DVB-T System using Outdoor Receiver Antenna with Masthead Amplifier}

During measurements, another important scenario has been identified. If the DVB-T antenna with a masthead amplifier receives simultaneous signals from interfering LTE FDD DL and GSM900 DL, a masthead amplifier overload occurs, causing PF. In general, due to the high rental and building expenses, mobile operator sites are multi-technology (GSM/ UMTS/ LTE).

Similar behavior has been investigated in [18] where performance of DVB-T/H services affected by interfering products of GSM and LTE mobile networks has been considered. Special attention was devoted to monitoring the interference with transmission parameter signaling (TPS) carriers, used in DVB-T/H system as reference information for the receiver [25]. 


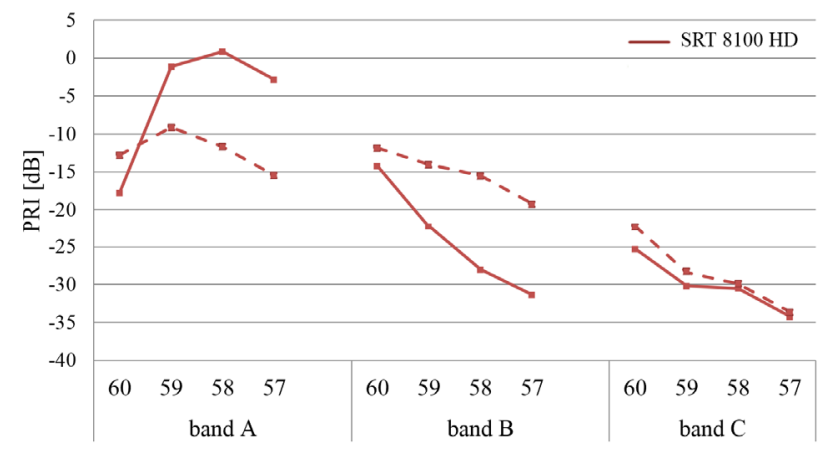

Fig. 10. Protection Ratio (PR) for DVB-T received signal $-70 \mathrm{dBm}$, DVB-T antenna system with masthead amplifier, simultaneous operation of GMS 900 and LTE idle (solid line) and GSM900 and LTE dedicated (dashed line).

Protection ratios in this scenario (Fig. 10) are extremely high, especially for LTE transmitting in band A and B. Another fact which differentiates this case from all previous scenarios is that greater interference is caused by the LTE signal in dedicated mode. This behavior can be explained by an overload effect caused by simultaneous presence of LTE and GSM signals, which has a major impact on the masthead amplifier in this case.

\section{Interference Mitigation Techniques}

In the process of DVB-T planning in a certain geographical area, the operator needs to fulfill minimum electric field strength $E$, expressed in $\mathrm{V} / \mathrm{m}(\mathrm{dBV} / \mathrm{m})$, or more often $\mu \mathrm{V} / \mathrm{m}(\mathrm{dB} \mu \mathrm{V} / \mathrm{m})$. Electric field strength in free space produces the flux density $S$. The available power at the receiver $P_{\mathrm{r}}$ is the product of the effective area of the receiving antenna $A_{\text {ef }}$, and the flux density $S$ at the location of the antenna:

$$
P_{\mathrm{r}}=S A_{\mathrm{ef}}=\left(\frac{E^{2}}{\eta}\right) \cdot\left(G_{\mathrm{r}} \frac{\lambda^{2}}{4 \pi}\right)=\frac{G_{\mathrm{r}} c^{2} E^{2}}{4 \pi \eta f^{2}} .
$$

The second equation in (1) is obtained by substituting the flux density and effective area of the antenna according to common expressions [30], while in the third one the signal wavelength $\lambda[\mathrm{m}]$ is expressed by the signal frequency $f[\mathrm{~Hz}]$ and the speed of light $c[\mathrm{~m} / \mathrm{s}]$. Here $\eta[\Omega]$ is the free space intrinsic impedance $(377 \Omega)$ and $G_{\mathrm{r}}[\mathrm{dBi}]$ is the receiving antenna gain.

In order to avoid degradation of the DVB-T signal reception and finally picture failure $(\mathrm{PF})$, the following protection ratio $(\mathrm{PR})$ criterion must be fulfilled:

$$
\frac{P_{\mathrm{r}, \mathrm{DVB}-\mathrm{T}}}{P_{\mathrm{r}, \text { interference }}} \geq P R \text {. }
$$

In (2) $P_{\mathrm{r}, \mathrm{DVB}-\mathrm{T}}$ is the received power of the desired television signal, while $P_{\text {r,interference }}$ is the total received power of all interfering signals (e.g. LTE, GSM, or any other). Both received powers $P_{\mathrm{r}}$ in (2) are expressed in linear power units (e.g. $\mathrm{mW}$ or $\mu \mathrm{W}$ ) while $P R$ is dimensionless quantity.
The alternative form of (2) in logarithmic units (e.g. dBm, dB) can be found in [18].

With the aim of making it easier to perceive measured PR thresholds, the results have been represented in terms of $\mathrm{PD}$, which is defined as the minimum required distance between interfering LTE DL antenna and receiving DVB-T antenna. The worst case scenario with LTE and DVB-T antennas (APXV90R20B-C [26], DTM-27 [34]) with main lobes looking one to the other and with clear line-of-sight in between has been assumed. Therefore, the Friis transmission equation (3) can be used:

$$
P_{\mathrm{r}}=\frac{P_{\mathrm{t}} G_{\mathrm{t}} G_{\mathrm{r}} \lambda^{2}}{(4 \pi d)^{2}}
$$

where $P_{\mathrm{t}}$ is the transmit power, $G_{\mathrm{t}}[\mathrm{dBi}]$ is transmitting LTE antenna gain, $G_{\mathrm{r}}[\mathrm{dBi}]$ receiving antenna gain and $d[\mathrm{~m}]$ is the distance between transmitting and receiving antennas. For calculation purposes, it has been assumed that the eNodeB transmits $2 \times 20 \mathrm{~W}(2 \times 2 \mathrm{MIMO})$, which together with $G_{\mathrm{t}}$, gives $61.8 \mathrm{dBm}$ of EIRP. Feeder loss has been ignored due to the main-remote eNodeB configuration, because remote radio unit has been installed on the top of the mast, close to the antenna. An additional $3 \mathrm{~dB}$ polarization loss has been taken into account.

An average PR (according to Figs $4,5,7$ ) of $-40 \mathrm{~dB}$ has been selected. DVB-T signal strength of $55 \mathrm{~dB} \mu \mathrm{V} / \mathrm{m}$ (Tab. 4), for the selected receiving DVB-T antenna is equal to $-70 \mathrm{dBm}$ signal power at the receiver. For the selected parameters and using (3), minimum distance $d$ between interfering LTE DL and receiving DVB-T antenna is $2668 \mathrm{~m}$. A DVB-T signal strength of $75 \mathrm{~dB} \mu \mathrm{V} / \mathrm{m}$ $(-50 \mathrm{dBm})$ reduces the minimum distance to $270 \mathrm{~m}$. However, in urban areas, a $270 \mathrm{~m}$ radius around the LTE site without at least a few DVB-T receiving antenna is almost unthinkable. Therefore, if criterion (2) cannot be fulfilled

\begin{tabular}{|c|c|c|c|c|c|c|}
\hline \multicolumn{5}{|c|}{ DVB-T field strength } & \multicolumn{2}{|c|}{$55[\mathrm{~dB} \mu \mathrm{V} / \mathrm{m}]$} \\
\hline \multicolumn{5}{|c|}{ DVB-T signal strength at the receiver $\left(G_{\mathrm{r}}=10 \mathrm{~dB}\right)$} & \multicolumn{2}{|c|}{$-70[\mathrm{dBm}]$} \\
\hline \multicolumn{5}{|c|}{ eNodeB output power } & \multicolumn{2}{|c|}{$2 \times 20[\mathrm{~W}]$} \\
\hline \multicolumn{5}{|c|}{ LTE antenna gain $\left(G_{\mathrm{t}}\right)$} & \multicolumn{2}{|c|}{$15.8[\mathrm{dBi}]$} \\
\hline \multicolumn{5}{|c|}{ Polarization Loss } & \multicolumn{2}{|c|}{$3[\mathrm{~dB}]$} \\
\hline $\begin{array}{l}\text { Additional } \\
\text { interference } \\
\text { attenuation } \\
\text { (filtering) } \\
\text { [dB] }\end{array}$ & 0 & 10 & 20 & 30 & 40 & 50 \\
\hline $\mathrm{PR}[\mathrm{dB}]$ & \multicolumn{6}{|c|}{$\mathrm{PD}[\mathrm{m}]$} \\
\hline-20 & 26678 & 8436 & 2668 & 844 & 267 & 84 \\
\hline-25 & 15002 & 4744 & 1500 & 474 & 150 & 47 \\
\hline-30 & 8436 & 2668 & 844 & 267 & 84 & 27 \\
\hline-35 & 4744 & 1500 & 474 & 150 & 47 & 15 \\
\hline-40 & 2668 & 844 & 267 & 84 & 27 & 8 \\
\hline-45 & 1500 & 474 & 150 & 47 & 15 & 5 \\
\hline-50 & 844 & 267 & 84 & 27 & 8 & 3 \\
\hline-55 & 474 & 150 & 47 & 15 & 5 & 2 \\
\hline-60 & 267 & 84 & 27 & 8 & 3 & 1 \\
\hline
\end{tabular}
for the specific $\mathrm{P}_{\mathrm{r}, \mathrm{DVB}-\mathrm{T}}$, measures have to be applied in order to attenuate $\mathrm{P}_{\mathrm{r} \text {,interference. Consequently, the required }}$

Tab. 4. Protection distance (PD). 
additional interference attenuation (Tab. 4) has been calculated for the specific PR in order to satisfy the PD criteria. For example, required $\mathrm{PR}$ is $-45 \mathrm{~dB}$. The distance between LTE interfering antenna and DVB-T receiving antenna is $200 \mathrm{~m}$, and cannot be optimized. Therefore, in order to satisfy minimum PD criteria, a filter with $20 \mathrm{~dB}$ attenuation should be applied in the DVB-T antenna system.

Several measures have been considered and proposed in CEPT reports 21, 22 [31], 23 and 30. Some of these relate to the way in which the LTE system already works (e.g. power control), and some require specific measures to be implemented at the LTE base station or DVB-T receiver side. Measures have been briefly discussed in [31]. However, applying antenna separation, coordination of antenna azimuths and tilts, and use of filtering have been identified as the most practical and cost effective measures to implement, and they have been analyzed in detail in studies [32] and [33].

\subsection{Applying Antenna Separation and Coordination of Antenna Azimuth and Tilt}

In this analysis, two typical commercial antenna products have been used: for the LTE system, antenna APXV90R20B-C [26], and for the DVB-T receiving system, antenna DTM-27 F [34].

The coordination of DVB-T and LTE antenna system can be considered in the horizontal and vertical plane. Theoretically, interference in the vertical plane can be reduced by positioning the DVB-T receiving antenna in the second null of the interfering LTE antenna.

From Fig. 11 a), interference suppression by positioning DVB-T antenna in the second null of interfering LTE antenna of $37 \mathrm{~dB}$ has been achieved, and an additional $3 \mathrm{~dB}$ interference suppression are coming from the DVB-T antenna vertical pattern. In Fig. 11 b), an additional $20 \mathrm{~dB}$ have been achieved by the DVB-T antenna vertical pattern due to the high back lobe suppression.

In the horizontal plane, the idea is to avoid placing the DVB-T receiving antenna in the LTE antenna horizontal main lobe. Since the LTE site has typically 3 sectors covering $360^{\circ}$ (Fig. 12), sufficient interference suppression

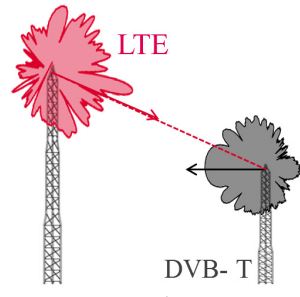

a)

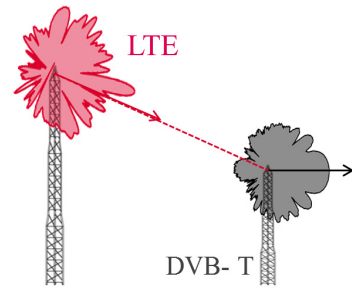

b)
Fig. 11. Interference suppression in vertical plane, exploiting the second null of the interfering LTE antenna in a) and high DVB-T antenna back lobe suppression in b).

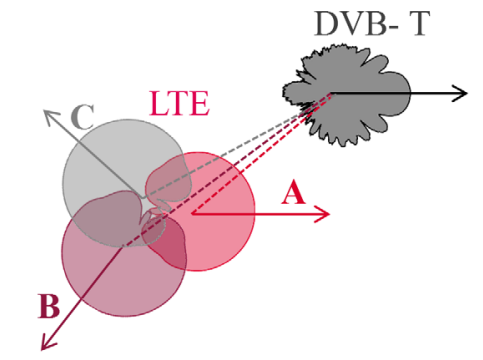

a)

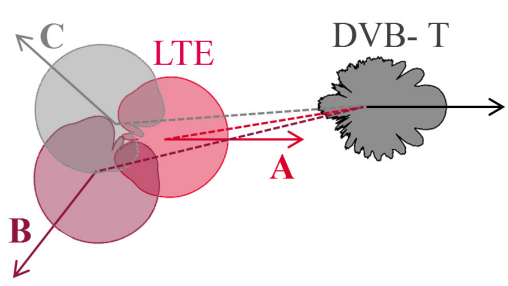

b)

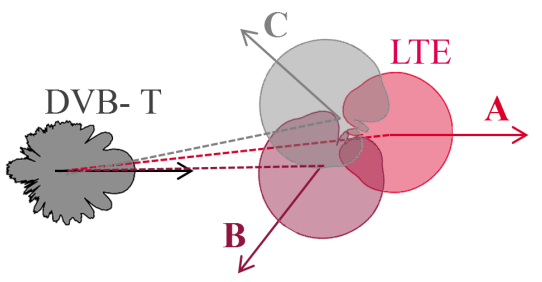

c)

Fig. 12. Interference suppression in horizontal plane, suppression of $30 \mathrm{~dB}$ achieved in a) and suppression of $15 \mathrm{~dB}$ achieved in $\mathrm{b}$ ) and c).

cannot be accomplished in practice. In the best case (Fig. $12 \mathrm{a}$ ), $30 \mathrm{~dB}$ of interference suppression can be reached, and in the two other cases, only $15 \mathrm{~dB}$ of interference suppression should be expected (Fig. 12 b, Fig. 12 c).

The proposed theoretical solution does not apply in practice because of the fact that mobile operators, due to optimization needs, often change their antennas azimuth and tilt. Furthermore, on a multitenant building, there is often more than one DVB-T receiving antenna system, which makes the proposed solutions impossible to apply.
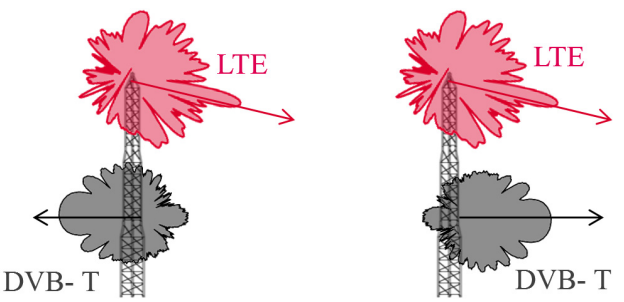

a)

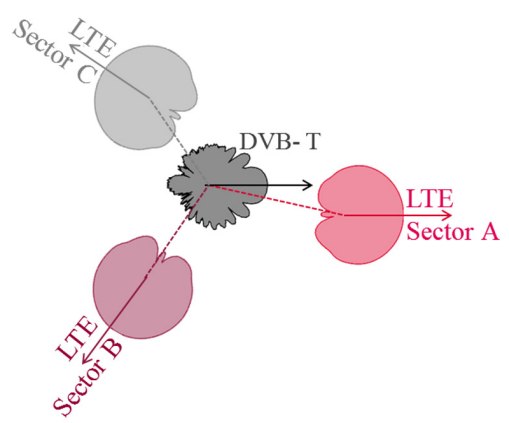

b)

Fig. 13. Practical interference suppression implementation in vertical a) and horizontal b) plane. 
However, modification of this proposed solution does have a strong practical implementation value (Fig. 13). Firstly, by collocating LTE and DVB-T antenna on the same mast (Fig. $13 \mathrm{a}$ ), 35-40 $\mathrm{dB}$ suppression thanks to the LTE antenna vertical pattern, and in addition $30 \mathrm{~dB}$ thanks to the DVB-T antenna vertical pattern can be achieved [32].

On multitenant buildings, mobile operator masts are usually placed in the middle of the building, for example, on the elevator housing. Sufficient isolation in the horizontal plane can be achieved (Fig. 13 b) by moving the LTE antenna sectors toward the corner of those building roofs. The number and orientation of DVB-T antennas do not affect the result. Furthermore, the mobile operator will achieve better coverage in the area close to site. The proposed solutions are cost effective too.

\subsection{Use of Filtering}

Filtering for downlink or power amplifier linearization techniques can be used to reduce unwanted emissions from a base station. Similarly, filtering at the DVB-T receiver side can be applied in order to reduce in-band interference from the base station. The second method has been identified as the most practical solution. Therefore, a study on the deviation of the filter response characteristics due to (environmental) temperature variation has been conducted [33]. According to the results of that study, special attention needs to be paid in the filtering product selection.

\section{Conclusion}

In the present paper, field measurements have been conducted for the fixed DVB-T reception environment to determine the most relevant interference scenarios and to quantify the Protection Ratio for each of these.

It has to be emphasized that DVB-T reception is more sensitive to eNodeB operating in idle mode, which could be related to the way the Automatic Gain Control (AGC) of the DVB-T receiver works. Significant PR increase occurs when a masthead amplifier has been used, and for interference generated from eNodeB and GSM900 base station simultaneously. A large number of households is still using masthead amplifiers and most mobile operator sites will be multi-technology (GSM/ UMTS/ LTE) in the near future. Therefore, this effect has to be seriously taken into account, and further investigated in future research.

Applying antenna separation, coordination of antenna azimuths or tilts and use of filtering have been elaborated and identified as the most practical and cost effective measures, and an effective deployment method has been proposed.

\section{References}

[1] ITU. Final Acts of the World Radiocommunication Conference (WRC-07). World Radiocommunication Conference, Geneva (Switzerland), 2007, p. 478-479. ISBN: 9261122019

[2] EUROPEAN COMMISSION - INFORMATION SOCIETY AND MEDIA DIRECTORATE-GENERAL, RADIO SPECTRUM COMMITTEE. Opinion of the RSC Pursuant to Article 4.2 of Radio Spectrum Decision 676/2002/EC. 6 pages. [Online] Cited 2015-06-04. Available at: http://ec.europa.eu/information_society /newsroom/image/3_april_2008_5769_draft_7481.pdf

[3] TEKOVIC, A., SIMAC, G., SAKIC, K. LTE downlink system performance measurement with intersystem interference caused by DVB-T signal. In Proceedings of the 54th International Symposium ELMAR. Zadar (Croatia), 2012, p. 255-258. ISSN 1334-2630

[4] SAKIC, K., GOSTA, M., GRGIC, S. Cross-border interference between broadcasting and mobile services. In Proceedings of the 51st International Symposium ELMAR. Zadar (Croatia), 2009, p. 229-232. ISBN 978-953-7044-10-7

[5] TEKOVIĆ, A. LTE in Digital Dividend deployment challengesDVB-C2 case. In Proceedings of the 54th International Symposium ELMAR, Zadar (Croatia), 2012, p. 251-254.

[6] KANG, D. H., ZHIDKOV, S. V., CHOI, H. J. An adaptive detection and suppression of co-channel interference in DVB-T/H system. IEEE Transactions on Consumer Electronics, 2010, vol. 56, no. 3, p. 1320-1327. DOI: 10.1109/TCE.2010.5606265

[7] GUIDOTTI, A., GUIDUCCI, D., BARBIROLI, M., et al. Coexistence and mutual interference between mobile and broadcasting systems. In Proceedings of the IEEE 73rd Vehicular Technology, Budapest (Hungary), 2011, p. 1-5. DOI: 10.1109/VETECS.2011.5956540

[8] SAKIC, K., GRGIC, S. The influence of the LTE system on DVB$\mathrm{T}$ reception. In Proceedings of the 52nd International Symposium ELMAR. Zadar (Croatia), 2010, p. 235-238.

[9] SETIAWAN, D., GUNAWAN, D., SIRAT, D. Interference analysis of guard band and geographical separation between DVB-T and E-UTRA in Digital Dividend UHF band. In Proceedings of the International Conference on Instrumentation, Communications, Information Technology, and Biomedical Engineering (ICICIBME). 2009, p. 1-6. DOI: 10.1109/ICICI-BME.2009.5417258

[10] CHEN, Y. X., XIAO, L., SUN, Y. Interference simulation from LTE to digital terrestrial television. In Proceedings of the 7th Wireless Communications, Networking and Mobile Computing Conference (WiCOM). Wuhan (China), 2011, p. 1-4. DOI: 10.1109/wicom.2011.6040068

[11] DAE-HEE KIM, SEONG-JUN OH, JUNGSOO WOO. Coexistence analysis between IMT system and DTV system in the $700 \mathrm{MHz}$ band. In Proceedings of the International Conference ICT Convergence (ICTC). Jeju (South Korea), 2012, p. 284-288. DOI: $10.1109 /$ ICTC.2012.6386840

[12] ALOISI, A., CELIDONIO, M., PULCINI, L., et al. Experimental study on protection distances between LTE and DVB-T stations operating in adjacent UHF frequency bands. In Proceedings of the Wireless Telecommunications Symposium (WTS). New York City (USA), 2011, p. 1-7. DOI: 10.1109/WTS.2011.5960859

[13] CELIDONIO, M., PULCINI, L., RUFINI, A. LTE and DVB-T coexistence: A simulation study in the UHF frequency band. Journal of Communication and Computer, 2012, vol. 9, no. 4, p. 444-455. 
[14] BARUFFA, G., FEMMINELLA, M., MARIANI, F., et al. Protection ratio and antenna separation for DVB-T/LTE coexistence issues. IEEE Communications Letters, 2013, vol. 17, no. 8, p. 1588 to 1591. DOI: 10.1109/LCOMM.2013.070113.130887

[15] MEHLFUHRER, C., WRULICH, M., IKUNO, J. C., et al Simulating the Long Term Evolution physical layer. In Proceedings of the 17th European Signal Processing Conference (EUSIPCO), 2009, p. 1471-1478.

[16] FUENTES, M., GARCIA-PARDO, C., GARRO, E., et al Coexistence of digital terrestrial television and next generation cellular networks in the $700 \mathrm{MHz}$ band. IEEE Wireless Communications, 2014, vol. 21, no. 6, p. 63-69. DOI: 10.1109/MWC.2014.7000973

[17] RIBADENEIRA-RAMIREZ， J., MARTINEZ, G., GOMEZBARQUERO, D., et al. Interference analysis between Digital Terrestrial Television (DTT) and 4G LTE mobile networks in the digital dividend bands. IEEE Transactions on Broadcasting, 2016 vol. 62, no. 1, p. 24-34. DOI: 10.1109/TBC.2015.2492465

[18] POLAK, L., KALlER, O., KLOZAR, L., et al. Mobile communication networks and digital television broadcasting systems in the same frequency bands: Advanced co-existence scenarios. Radioengineering, 2014, vol. 23, no. 1, p. 375-386.

[19] POLAK, L., KALLER, O., KLOZAR, L., et al. Influence of mobile network interfering products on DVB-T/H broadcasting services. In Proceedings of the Wireless Days (IFIP). 2012, p. 1-5. DOI: 10.1109/WD.2012.6402860

[20] KRISTEL, J., POLAK, L., KRATOCHVIL, T. Co-channe coexistence between DVB-T/H and LTE standards in a shared frequency band. In Proceedings of the 25th International Conference RADIOELEKTRONIKA. Pardubice (Czech Rep.), 2015, p. 184-190. DOI: 10.1109/RADIOELEK.2015.7129004

[21] De VITA, A., MILANESIO, D., SACCO, B., et al. Assessment of interference to the DTT service generated by LTE signals on existing head amplifiers of collective distribution systems: A real case study. IEEE Transactions on Broadcasting, 2014, vol. 60, no. 2 , p. 420-429. DOI: 10.1109/TBC.2014.2321677

[22] POLAK, L., KAller, O., KlOZAR, L., et al. Coexistence between DVB-T/T2 and LTE standards in common frequency bands. Wireless Personal Communication, 2016, vol. 88, no. 3, p. 669-684. DOI: $10.1007 / \mathrm{s} 11277-016-3191-2$

[23] POLAK, L., KAller, O., KLOZAR, L., et al. Study of coexistence between indoor LTE femtocell and outdoor-to-indoor DVB-T2-Lite reception in a shared frequency band. EURASIP Journal of Wireless Communication and Networking, 2015, no. 114,14 p. DOI: 10.1186/s13638-015-0338-x

[24] ELECTRONIC COMMUNICATIONS COMMITTEE (ECC). Measurements on the Performance of DVB-T Receivers in the Presence of Interference from the Mobile Service- Especially from LTE (ECC Report 148). 32 pages. [Online] Cited 2015-06-04. Available at: http://www.erodocdb.dk/Docs/doc98/official/pdf/ ECCREP148.pdf

[25] EUROPEAN TELECOMMUNICATIONS STANDARDS INSTITUTE (ETSI). Digital Video Broadcasting (DVB); Framing Structure, Channel Coding and Modulation for Digital Terrestrial Television (DVB-T) (Recommendation ETSI EN 300744 V1.6.1). 66 pages. [Online] Cited 2015-06-04. Available at: http://www.etsi.org/deliver/etsi_en/300700_300799/300744/01.06. 01_60/en_300744v010601p.pdf

[26] RADIO FREQUENCY SYSTEMS (RFS). APXV9R20B-C Antenna Model (datasheet). 2 pages [Online] Cited 2015-06-04. Available at: http:/www.rfsworld.com/websearch/Datasheets/pdf/ $? \mathrm{q}=\mathrm{APXV} 9 \mathrm{R} 20 \mathrm{~B}-\mathrm{C}$

[27] HOLMA, H., TOSKALA, A. LTE for UMTS OFDMA and SCFDMA Based Radio Access. $1^{\text {st }}$ ed. John Wiley \& Sons Ltd., 2009. ISBN: 9780470994016
[28] PARKER, I., MUNDY, S. Assessment of LTE $800 \mathrm{MHz}$ Base Station Interference into DTT Receivers (ERA Technology for OFCOM, Report 2011-0351). 41 pages. [Online] Cited 2015-0604. Available at: http://stakeholders.ofcom.org.uk/binaries/ consultations/dtt/annexes/Ite-800-mhz.pdf

[29] FTE MAXIMAL LG 222 Reception Masthead Amplifier (datasheet). 2 pages [Online] Cited 2015-07-17. Available at: http: //ftemaximal.com/images/files/soporte-servicios/Documentaciontecnica/MALG227.pdf

[30] BALANIS, A. C., Antenna Theory: Analysis and Design. $3^{\text {rd }}$ ed. New Jersey (USA): John Wiley \& Sons Ltd., 2005. ISBN 978-0471-66782-7

[31] EUROPEAN CONFERENCE OF POSTAL AND TELECOMMUNICATIONS ADMINISTRATIONS (CEPT). Technical Considerations Regarding Harmonization Options for the Digital Dividend (CEPT Report 22). 52 pages. [Online] Cited 2015-06-04. Available at: http://www.erodocdb.dk/docs/doc $98 /$ official/pdf/CEPTRep022.pdf

[32] BONEFAČIĆ, D., ŠIŠUL, G. Mobile Communications System (LTE) in the Frequency Range of the Digital Dividend with the Digital Television System (DVB-T) Interference Analysis (Report 2012-4500243244). Faculty of Electrical Engineering and Computing for VIPnet Ltd., 97 pages. (in Croatian)

[33] BONEFAČIĆ, D. Testing of Filters for Interference Suppression from LTE System into DVB-T System. (Report 2013- 4500267607). Faculty of Electrical Engineering and Computing for VIPnet Ltd., 44 pages. (in Croatian)

[34] ISKRA. DTM-27 F Antenna Model (datasheet). 1 page. [Online] Cited 2015-06-04. Available at: http: http://www.iskra.eu/

\section{About the Authors...}

Alberto TEKOVIĆ received his Mag. Ing. El. and M. Sc. in Electrical Engineering from the Faculty of Electrical Engineering, University of Zagreb, Croatia in 2000 and 2005 , respectively. He is currently employed as a Radio Network Optimization Expert in the mobile operator VIPnet Ltd. He is also engaged as a senior lecturer at the University College for Applied Computer Engineering and Polytechnic of Zagreb, and teaching activities include several subjects on mobile networks: Mobile Radiocommunications and Wireless Computer Networks. He published one book and more than 10 scientific papers in journals and conference proceedings. From 2012 he organizes a special session related to modern mobile networks, as a part of the International Symposium ELMAR. In 2015 he served as a committee member on the Microwave and Radio Electronics Week - MAREW. His research interests are in the field of wireless communications, mobile network performance optimization and radio propagation.

Davor BONEFAČIĆ received his Dipl. Ing., Mr. Sc. and Dr. Sc. degrees in Electrical Engineering from the University of Zagreb, Faculty of Electrical Engineering and Computing (FER), Zagreb, Croatia, in 1993, 1996 and 2000, respectively. In 1993 he joined the Department of Wireless Communications at the Faculty of Electrical Engineering and Computing in Zagreb. Today he is Full Professor at the same Department. In 1996 he was a visiting researcher at the Third University of Rome, Rome, Italy. His research interests are in the field of small and integrated antennas, 
textile antennas and waveguiding structures, and on-body communications. He is currently leading a research project on textile antennas financed by the Croatian Science Foundation. He published one book chapter and more than 90 scientific papers in journals and conference proceedings. In the 2003-2014 period, he served as a member of the editorial board of Radioengineering journal. He was also the editor of eleven international conference proceedings in printed and electronic form. He is co-author of one university textbook. His teaching activity includes several subjects on microwave engineering, RF systems, antennas and radars at graduate and doctoral studies. His professional activities are in the field of EMC, EMI estimation and suppression, EM field measurement and estimation of human exposure to EM fields. He authored and co-authored more than 35 professional and technical papers for government entities and companies. He is a member of the Croatian Academy of Engineering (HATZ) and he was elected Secretary of the Dept of Communication Systems of the Academy for the 2013-2017 term. He is a senior member of IEEE, chair of the MTT Chapter of the IEEE Croatia Section for the term 2011-2015 and vice-chair of the joint AES/GRS Chapter for the term 2015-2017. He received the silver plaque "J. Lončar" from FER for outstanding master thesis in 1996. In 2009 he received the
"Rikard Podhorsky" award from the Croatian Academy of Engineering (HATZ) for excellence in scientific and professional achievements.

Gordan ŠIŠUL received his B.Sc., M.Sc. and Ph.D. in Electrical Engineering from the Faculty of Electrical Engineering, University of Zagreb, Croatia in 1996, 2000 and 2004, respectively. He is currently employed as an Associate Professor at the same Faculty. His academic interests include wireless communications, signal processing applications in communications, modulation techniques and radio propagation.

Robert NAÐ received his Dipl.Ing. Mr.Sc. and Dr.Sc. degrees in Electrical Engineering from the University of Zagreb, Faculty of Electrical Engineering and Computing (FER), Zagreb, Croatia. He is currently employed as a Full Professor at the same Faculty. He is co-author of two university textbooks. His teaching activity includes several subjects on modern mobile networks at graduate and doctoral studies: Mobile Communications, Mobile Systems Planning, Signal Equalization in Wireless Transmission and Spread Spectrum Systems. His academic interests are related to the analysis of physical phenomena in radio channel and its impact on modulation and radio propagation and wireless communications in general. 